\title{
PROSPECTIVE RANDOMIZED TRIAL OF EFFICACY AND SAFETY OF IODOPOVIDONE VS OXYTETRACYCLINE FOR PLEURODESIS IN SPONTANEOUS PNEUMOTHORAX AND RECURRENT PLEURAL EFFUSIONS
}

\author{
Uday C. Kakodkar1, Sanjivani J. Keny², Mujeeb Rehman P. C ${ }^{3}$ \\ ${ }^{1}$ Assistant Professor, Department of Pulmonary Medicine, Goa Medical College, Goa. \\ ${ }^{2}$ Lecturer, Department of Pulmonary Medicine, Goa Medical College, Goa. \\ ${ }^{3}$ Ex. Junior Resident, Department of Pulmonary Medicine, Goa Medical College, Goa.
}

\section{ABSTRACT}

\section{BACKGROUND}

Recurrent malignant pleural effusion and spontaneous pneumothorax can be treated by a procedure called pleurodesis by which the pleural space is obliterated. This can be done by surgical means using mechanical force or by introducing any one of the recommended agents into the pleural space via tube thoracostomy or during thoracoscopy. Examples of agents used are talc as powder or as slurry, tetracycline derivatives, antineoplastic agents (Bleomycin, mitoxantrone), quinacrine, silver nitrate, Corynebacterium parvum and iodopovidone. The aim of the present study was to evaluate the safety and efficacy of iodopovidone as a sclerosing agent in the treatment of recurrent pleural effusion and spontaneous pneumothorax. This was a randomized prospective interventional study comparing iodopovidone with oxytetracycline as the latter is now sparingly available for clinical use.

\section{MATERIAL AND METHODS}

Study was conducted in 44 patients above 12 years of age, admitted in the Dept. of Pulmonary Medicine, Goa Medical College. Patients with a diagnosis of spontaneous pneumothorax or recurrent malignant pleural effusion were randomly allocated to either iodopovidone or oxytetracycline group and pleurodesis was done as per British Thoracic Society Guidelines (BTS). ${ }^{1}$

\section{RESULTS}

Among 44 patients 23 were secondary spontaneous pneumothorax, 9 were primary spontaneous pneumothorax and 12 were malignant pleural effusion; 2 patients did not report for follow-up visits and the remaining 42 patients were followed up for 6 months. The success rate of oxytetracycline and iodopovidone pleurodesis is $81 \%$ and $95.2 \%$ respectively. All the patients had chest pain of varying severity during the procedure in either groups; 8 patients in oxytetracycline group and 6 patients in iodopovidone group had fever after the procedure; 2 patients in iodopovidone group developed hypotension after the procedure and there was no mortality in either group attributable to the procedure.

\section{CONCLUSIONS}

Iodopovidone as a pleural sclerosant is comparable with oxytetracycline as regards its efficacy and safety profile. The success rate of iodopovidone pleurodesis is superior to that of oxytetracycline pleurodesis; however, the difference is statistically not significant $(\mathrm{p}<0.005)$. Iodopovidone is an effective, safe, readily available alternative to oxytetracycline as a sclerosing agent in recurrent incapacitating effusions and spontaneous pneumothoraces, regardless of their etiology.

\section{KEYWORDS}

Pleurodesis, Spontaneous Pneumothorax, Pleural Effusion.

HOW TO CITE THIS ARTICLE: Kakodkar UC, Keny SJ, Mujeeb Rehman PC. Prospective randomized trial of efficacy and safety of iodopovidone vs. oxytetracycline for pleurodesis in spontaneous pneumothorax and recurrent pleural effusions. J. Evolution Med. Dent. Sci. 2016;5(14):653-658, DOI: 10.14260/jemds/2016/150

\section{INTRODUCTION}

The pleura is the serous membrane that covers the lung parenchyma, mediastinum, diaphragm and the rib cage. A small amount of fluid $(0.01 \mathrm{~mL} / \mathrm{kg} / \mathrm{hr})$ enters the pleural space from capillaries of parietal pleura. ${ }^{2}$ The capacity of the pleural lymphatics to absorb the fluid is 20 times the rate of formation $(0.2 \mathrm{~mL} / \mathrm{kg} / \mathrm{hr})$, hence only $15-30 \mathrm{~mL}$ of fluid is normally present in the potential pleural space. ${ }^{3}$

Financial or Other, Competing Interest: None.

Submission 05-01-2016, Peer Review 30-01-2016,

Acceptance 05-02-2016, Published 18-02-2016.

Corresponding Author:

Dr. Uday C. Kakodkar,

24, Azad Co-op. Housing Society,

Curca, P. O. Goa Velha,

Tiswadi-403108, Goa.

E-mail:drudayk@hotmail.com

DOI: $10.14260 /$ jemds/2016/150
The pleural effusion occurs when the rate of pleural fluid formation exceeds the rate of fluid absorption. The other mechanism being the blockage of the lymphatic channels by malignant deposits. Recurrent pleural effusions and spontaneous pneumothoraces can be treated by pleurodesis, by which the pleural space is obliterated. This can be done by surgical means using mechanical force or by introducing any one of the recommended agents into the pleural space via tube thoracostomy or during thoracoscopy. Examples of agents used are talc. ${ }^{4}$ as powder or as slurry, tetracycline.$^{5}$ derivatives (Oxytetracycline, doxycycline. ${ }^{6}$ minocycline), antineoplastic agents (Bleomycin, mitoxantrone), quinacrine. ${ }^{7}$, silver nitrate. ${ }^{8}$, Corynebacterium parvum. ${ }^{9}$ and iodopovidone. ${ }^{10}$

Oxytetracycline is very sparingly available in the market due to rarity of its use as an antibiotic. Hence, the present study was undertaken to evaluate the efficacy and safety of an 
alternative agent and compare it with oxytetracycline which was being used for more than 20 years in our department.

\section{MATERIALS AND METHODS Population of Study}

This is a prospective randomized interventional study using chemical agents either oxytetracycline or iodopovidone for intrapleural instillation as sclerosing agents. A prior approval of Institutional Ethics Committee of Goa Medical College was obtained.

The study was conducted in 44 patients admitted in the Dept. of Pulmonary Medicine, Goa Medical College. Patients with a diagnosis of spontaneous pneumothorax or recurrent malignant pleural effusion who were fulfilling the inclusion criteria were taken for the study. The patients included in this study as pleural effusion had cytological or histological evidence of malignancy at the primary site and had exudative pleural effusion. The pleural effusion was refilling and needed repeating thoracentesis to relieve breathlessness. The patient with exudative pleural effusion due to unknown primary showed pleural fluid cytology positive for malignant cells. A written and informed consent was obtained from all the patients included in the study.

\section{Selection of Patient}

If the patient with spontaneous pneumothorax was symptomatic, an intercostal tube was passed under strict aseptic precautions and connected to underwater seal drainage system. Pleurodesis was performed 24 hours following total expansion of the lung. Patients admitted with pleural effusion were evaluated to find out etiology of the effusion by pleural fluid analysis, chest USG, flexible bronchoscopy and CECT of the thorax.

Patients with refilling or recurrent symptomatic effusions who were candidates for pleurodesis, intercostal tube was passed as per standard guidelines. The patient was taken up for pleurodesis in pneumothorax and in recurrent pleural effusion once the underlying lung had fully expanded, the same was duly confirmed with a CXR.

\section{Inclusion Criteria}

A patient admitted with either a spontaneous pneumothorax or a recurrent pleural effusion; age $>12$ years.

\section{Exclusion Criteria}

Known hypersensitivity to iodine, known hypersensitivity to oxytetracycline, known thyroid disease, terminally ill patients, hemodynamically unstable patient, uncooperative patient, history of pleurodesis in the past.

\section{Oxytetracycline Group}

A $3 \mathrm{mg} / \mathrm{kg}$ of $2 \%$ lignocaine was taken in a sterile $20 \mathrm{cc}$ syringe and was made up to $20 \mathrm{cc}$ with sterile normal saline. This was introduced into pleural cavity through the intercostal tube after clamping it; 20 minutes later $35 \mathrm{mg} / \mathrm{kg}$ of oxytetracycline was aspirated in a sterile $50 \mathrm{cc}$ syringe and diluted up to $50 \mathrm{cc}$ with sterile normal saline. This was also introduced into the pleural cavity slowly; $20 \mathrm{cc}$ of sterile normal saline was then introduced to flush the tube.

\section{Iodopovidone Group}

A $2 \%$ lignocaine was introduced as explained for oxytetracycline group into the pleural cavity.
After 20 minutes, $20 \mathrm{cc}$ of $10 \%$ iodopovidone and $80 \mathrm{cc}$ of sterile normal saline was added to make the volume of $100 \mathrm{~mL}$ of $2 \%$ iodopovidone. This was introduced into pleural cavity slowly.

Pulse rate, respiratory rate, blood pressure and the temperature were recorded. Those who complained of pain during introduction of the sclerosant into the pleural cavity were given $1 \mathrm{mg}$ of injection midazolam IV.

The temperature was recorded every $4^{\text {th }}$ hourly for the next 24 hours. The intercostal tube was retained for the next 24 hours in cases of pneumothoraces and was removed when the drainage was $<100 \mathrm{~mL} / 24$ hours in cases of pleural effusions. The patient was observed in the hospital 24 hours after removal of the tube. CXR was done in all the patients prior to the discharge from the hospital.

\section{Followup}

During regular visits to the outpatient clinic at the end of 1 st, $3^{\text {rd }}$ and $6^{\text {th }}$ month from the day of discharge CXR was repeated.

\section{OBSERVATIONS AND RESULTS}

\section{Age and Sex Distribution}

Age of the patients varied from 17 to 80 years. The mean age of the patients in oxytetracycline and iodopovidone group was 51.64 and 49.32 respectively. There were 30 males and 14 females.

\section{Diagnosis in the Studied Patients}

Out of 44 patients, 32 had spontaneous pneumothorax and 12 with malignant pleural effusion. In oxytetracycline group, 17 were spontaneous pneumothoraces and 5 were malignant pleural effusions and in iodopovidone group 15 were spontaneous pneumothoraces, 7 being malignant pleural effusions. Table 1 shows primary site for malignant pleural effusion.

\begin{tabular}{|c|c|c|c|}
\hline & Oxytetracycline & Iodopovidone & Total \\
\hline Carcinoma lung & 2 & 2 & 4 \\
\hline Carcinoma ovary & 0 & 3 & 3 \\
\hline Carcinoma colon & 0 & 1 & 1 \\
\hline Cancer of cervix & 1 & 0 & 1 \\
\hline Cancer of breast & 0 & 1 & 1 \\
\hline $\begin{array}{c}\text { Unknown } \\
\text { primary }\end{array}$ & 2 & 0 & 2 \\
\hline \multicolumn{2}{|c|}{$\begin{array}{l}\text { Table 1: Showing causes of malignant effusion in } \\
\text { oxytetracycline and iodopovidone group }\end{array}$} \\
\hline
\end{tabular}

\section{Distribution of Spontaneous Pneumothorax Patients Each Group}

Thirty two patients had spontaneous pneumothorax; 9 being primary and 23 secondary spontaneous pneumothoraces (52.57\%). Oxytetracycline group had 5 and iodopovidone group had 4 cases of primary spontaneous pneumothoraces. Of 23 patients with secondary spontaneous pneumothorax, 12 were in oxytetracycline group and 11 in iodopovidone group.

\section{Distribution of Causes of Secondary Spontaneous Pneumothorax}

The secondary spontaneous pneumothoraces were either due to COPD $(n=14)$, sequelae of pulmonary tuberculosis $(n=7)$ or both COPD and pulmonary tuberculosis $(n=2)$. 
Distribution of Side Effects of Pleurodesis

Table 2 analyses the side effects due to pleurodesis in either groups.

\begin{tabular}{|c|c|c|c|}
\hline & $\begin{array}{c}\text { Oxytetracycline } \\
(\%)\end{array}$ & $\begin{array}{c}\text { Iodopovidone } \\
(\%)\end{array}$ & $\begin{array}{l}\text { Total } \\
(\%)\end{array}$ \\
\hline Chest pain & $22(100)$ & $22(100)$ & $44(100)$ \\
\hline Fever & $8(36.4)$ & $6(27.3)$ & $14(32)$ \\
\hline Hypotension & 0 & $2(4.55)$ & $2(4.55)$ \\
\hline
\end{tabular}

Out of the 22 patients of oxytetracycline group, only 2 (9\%) had severe chest pain and 20 (91\%) had either mild or moderate pain. In iodopovidone group, only $4(18 \%)$ had mild pain and $18(82 \%)$ patients had moderate or severe pain. This difference is statistically significant $(\mathrm{p}<0.05) ; 14 \quad(32 \%)$ patients developed fever. In oxytetracycline group incidence of fever was $8(36 \%)$ and in iodopovidone group it was 6 $(27 \%)$. Of the total 22 patients in each group, $8(57 \%)$ in oxytetracycline group and $6(43 \%)$ in iodopovidone group developed fever. The difference in the incidence of fever between the two group is statistically insignificant $(p<0.03)$.

Out of 44 patients 42 were available for follow-up, 37 patients improved and there was no recurrence of either pleural effusion or pneumothorax in the follow-up period. So the overall success rate is $88.1 \%$ ( $81 \%$ for oxytetracycline group and $95.2 \%$ in iodopovidone group).

\begin{tabular}{|c|c|c|c|}
\hline & Oxytetracycline & Iodopovidone & Total \\
\hline $\begin{array}{c}\text { Success } \\
\text { Rates }\end{array}$ & $17(81 \%)$ & $20(95.2 \%)$ & $37(88.1 \%)$ \\
\hline $\begin{array}{c}\text { Failure } \\
\text { Rates }\end{array}$ & $4(19 \%)$ & $1(4.8 \%)$ & $5(11.9 \%)$ \\
\hline $\begin{array}{c}\text { Drop- } \\
\text { outs }\end{array}$ & 1 & 1 & 2 \\
\hline Total & 22 & $\mathbf{2 2}$ & $\mathbf{4 4}$ \\
\hline \multicolumn{4}{|c|}{$\begin{array}{r}\text { Table 3: Showing the outcome of the chemical } \\
\text { pleurodesis in the studied patients in each group }\end{array}$} \\
\hline
\end{tabular}

Four patients from oxytetracycline and one patient from iodopovidone group had failed pleurodesis.

\section{Outcome of Pleurodesis According to Initial Diagnosis}

Out of the 42 patients, $100 \%$ success was reported for patients who underwent pleurodesis for primary and secondary spontaneous pneumothorax. But in patients with malignant effusion success rate was only $58.3 \%$ and failure rate was $41.7 \%$. The low success rate in malignant pleural effusion could be attributed to the fact that in 9 out of 12, pleurodesis was attempted in patients who had already received treatment for primary malignancy in the form of surgery and/or chemoradiotherapy and yet had metastatic disease in pleura when the patient was referred to our department for pleurodesis.

\section{Comparison of Outcomes of Pleurodesis in Patients of Malignant Effusion in Each Group}

Success rate of oxytetracycline pleurodesis in patients with malignant effusion is only $20 \%$, whereas with iodopovidone pleurodesis it is $86 \%$. This difference is statistically significant $(\mathrm{p}<0.03)$.
Distribution of Mortality According to the Diagnosis

There were no deaths in spontaneous pneumothorax group during the study period; 6-month mortality rate of malignant pleural effusion patients was $66.7 \%$. However, none of these deaths can be attributed to procedure as all these have died due to the underlying malignancy.

\begin{tabular}{|c|c|c|c|}
\hline & $\begin{array}{c}\text { Mortality } \\
\text { (No.) }\end{array}$ & Total & $\begin{array}{c}\text { Mortality } \\
\text { (\%) }\end{array}$ \\
\hline $\begin{array}{c}\text { Malignant } \\
\text { effusion }\end{array}$ & 8 & 12 & $66.7 \%$ \\
\hline $\begin{array}{c}\text { Primary } \\
\text { pneumothorax }\end{array}$ & 0 & 9 & $0 \%$ \\
\hline $\begin{array}{c}\text { Sec. } \\
\text { pneumothorax }\end{array}$ & 0 & 23 & $0 \%$ \\
\hline \multicolumn{2}{|c|}{ Table 4: Shows distribution of mortality } \\
according to the diagnosis
\end{tabular}

\section{DISCUSSION}

The management of recurrent pleural effusion or pneumothorax has always been a serious concern among the chest physicians. A patient who had a spontaneous pneumothorax is at risk of having a recurrence. Sadikot et al.11 followed up 153 patients with primary spontaneous pneumothorax for a mean of 54 months and found that the recurrence rate was $54.2 \%$. Gobbel et al. ${ }^{12}$ followed a group of 119 patients with spontaneous pneumothorax for a mean period of 6 years. These investigators found that of 110 patients who did not undergo thoracotomy at the time of first pneumothorax, 52\% had an ipsilateral recurrence. Once a patient had second and third pneumothorax without thoracotomy, the incidence of subsequent recurrence was $62 \%$ and $83 \%$ respectively.

Recurrence rates for secondary spontaneous pneumothorax appear to be somewhat higher than those for primary spontaneous pneumothorax. Videm et al. ${ }^{13}$ reported that 24 of the 54 patients (44\%) with COPD had a recurrence. In patients without COPD, 96 of 249 (39\%) had a recurrence. In VA (Veterans Affairs) cooperative study.14, 92 patients with secondary pneumothorax were treated with chest tubes without pleurodesis and the recurrence rate was $47 \%$ with a median follow-up of 3 years. In this study, the recurrence rate with primary spontaneous pneumothorax was $32 \%$.

The reported recurrence of pneumothorax after treating with tube thoracostomy without pleurodesis is similar to that of initial episode treated by bed rest alone. So it is recommended that all patients with primary or secondary spontaneous pneumothorax who are treated with tube thoracostomy should receive an intrapleural sclerosing agent unless they are subjected to thoracoscopy or thoracotomy. 15

Malignant pleural effusions are frequent contributors to the morbidity in patients with a variety of underlying cancers. The onset of malignant pleural effusion compromises the wellbeing of patient by causing symptoms of dyspnea and exercise intolerance and may contribute to mortality from the underlying disease.

Chemical pleurodesis is a well-accepted, palliative therapy for patients with recurrent malignant pleural effusions. The goal of pleurodesis in this population therefore is to palliate symptoms and improve the quality of life with a well-tolerated, effective, economical and safe procedure. Tetracycline derivatives have been accepted for chemical pleurodesis since many years. 
Initially oxytetracycline was used for pleurodesis. Many studies have already proved its efficacy as intrapleural sclerosant. In our hospital, pleurodesis is being performed for more than 20 years for pneumothoraces and effusions using oxytetracycline as a sclerosing agent. However, it is not freely available nowadays on account of rarity of its use as antibiotic and stringent manufacturing guidelines.

This study is performed in the background of search for an ideal agent for pleurodesis. In this study we did pleurodesis on 44 patients; 22 with oxytetracycline which is the agent currently used and 22 with iodopovidone which is a newer recommended agent for pleurodesis.

The high success rate in the present study can be attributed to following reasons. Pleurodesis agent was introduced only after ensuring that the lung has fully expanded. The presence of proximal obstruction was excluded by bronchoscopy, CT scan of the thorax whenever indicated. Patients with spontaneous pneumothorax were advised not to perform any strenuous activities, not to lift heavy weights during the study period. Counseling was done at every followup visits to ensure strict abstinence from smoking. However, small size of the study population and shorter follow-up period could also be the reason for higher success rate in the present study.

The success rates of oxytetracycline pleurodesis in the various studies is compared in Table 5.

\begin{tabular}{|c|c|c|}
\hline Study & $\begin{array}{c}\text { Number of } \\
\text { Patients }\end{array}$ & $\begin{array}{c}\text { Success } \\
\text { Rate }\end{array}$ \\
\hline Veterans study (VA). ${ }^{14}$ & 229 & $75 \%$ \\
\hline Alfageme et al. ${ }^{16}$ & 66 & $91 \%$ \\
\hline Sherman et al. ${ }^{17}$ & 108 & $94.4 \%$ \\
\hline Walker et al.18 & 359 & $67 \%$ \\
\hline Present study & 22 & $81 \%$ \\
\hline \multicolumn{2}{|c|}{ Table 5: Showing success rates of } \\
oxytetracycline pleurodesis \\
\hline
\end{tabular}

\section{Success Rate of Iodopovidone Pleurodesis}

In the present study, 21 patients underwent iodopovidone pleurodesis, success rate being $95.2 \%$. The success rate in the present study is comparable with the other studies. OlivaresTores, et al. ${ }^{19}$ published one study on iodopovidone pleurodesis in 2002 in which success rate was 96\%; 40 (out of 52) patients underwent pleurodesis after thoracoscopy and 12 patients after tube thoracostomy. Table 6 compares the success rates of iodopovidone pleurodesis in various studies.

\begin{tabular}{|c|c|c|}
\hline Study & $\begin{array}{c}\text { Patients } \\
\text { (no.) }\end{array}$ & $\begin{array}{c}\text { Success Rate } \\
(\%)\end{array}$ \\
\hline $\begin{array}{l}\text { Olivares-Tores et } \\
\text { al.19 }\end{array}$ & 52 & $96 \%$ \\
\hline Dey et al. ${ }^{20}$ & 37 & $89.5 \%$ \\
\hline $\begin{array}{l}\text { Morales-Gomez } \\
\quad \text { et al. }{ }^{21}\end{array}$ & 39 & $91.6 \%$ \\
\hline Kelly-Garcia et al. ${ }^{22}$ & 14 & $64.2 \%$ \\
\hline Present Study & 21 & $95.2 \%$ \\
\hline \multicolumn{3}{|c|}{$\begin{array}{c}\text { Table 6: Showing success rates of iodopovidone } \\
\text { pleurodesis in various studies }\end{array}$} \\
\hline
\end{tabular}

The success rate of Olivares et al. is significantly higher as compared to other studies because pleurodesis was performed at the end of diagnostic thoracoscopy during which fluid loculations and pleural adhesions can be eliminated. Success rate of the present study is comparable and it is as good as Olivares study, even though in the present study pleurodesis was done through tube thoracostomy.

From the above discussion, it is clear that iodopovidone pleurodesis through the tube thoracostomy (95.2\%) is comparable to the iodopovidone pleurodesis after thoracoscopy (96\%). This is important because pleurodesis can be done even in peripheral institutes through the tube thoracostomy where thoracoscopic procedures are unavailable. So the results of iodopovidone pleurodesis through tube thoracostomy are superior to post thoracoscopic iodopovidone pleurodesis as it needs less expertise, shorter hospitalization period and hence is economical too.

Success rate of pleurodesis of the present study for spontaneous pneumothorax is $100 \%$. There were no recurrences of spontaneous pneumothorax in either oxytetracycline or iodopovidone group. If no treatment is done in cases of spontaneous pneumothorax to prevent its recurrence then failure is $54 \%$. So any patient with either primary or secondary spontaneous pneumothorax, a procedure is mandatory to prevent its recurrence and chemical pleurodesis with iodopovidone is a better choice.

\section{Comparison between Oxytetracycline and Iodopovidone \\ Pleurodesis}

In the present study with 21 patients in each group of pleurodesis, success rate is $95.2 \%$ for iodopovidone group compared to $81 \%$ in oxytetracycline group. Both the groups had almost identical distribution of patients in terms of diagnosis. The difference between the success rates of the pleurodesis is statistically insignificant $(p<0.05)$ and their efficacy is comparable. The present and previous studies prove that iodopovidone is as effective as oxytetracycline for pleurodesis, former having the edge since it is easily available and is cheaper.

\section{Side Effects of Pleurodesis}

The most common side effects of chemical pleurodesis are chest pain and fever. In this study, 22 patients underwent pleurodesis with oxytetracycline. All the patients had chest pain during introduction of sclerosant into the pleural cavity. Severity of pain was graded as mild, moderate, severe and excruciating pain based on the need for oral and/or parenteral analgesics. $91 \%$ had mild or moderate and $9 \%$ had severe pain. In the Veterans Administration cooperative study $50 \%$ of the patients experienced severe pain during pleurodesis.

Incidence of pain in iodopovidone group was also $100 \%$, with $82 \%$ of the patients experiencing either moderate or severe pain. The incidence of severe pain was $41 \%$. The differences in the pain experienced during pleurodesis in the present study and in various published studies may be due to the different parameters used to assess pain. In the present study, pain assessment was purely subjective and it is dependent on the patient's threshold to tolerate pain which varies from individual to individual.

In the pioneer study with iodopovidone by OlivaresTores et al. 3 (5.8\%) of the 58 patients experienced intense pain during pleurodesis. In a study conducted in Kolkata. ${ }^{20}, 3$ (7.9\%) of the 38 patients had intense pain. In the present study, $1(4.4 \%)$ patient had excruciating pain during pleurodesis. 


\begin{tabular}{|c|c|c|c|}
\hline Study & $\begin{array}{c}\text { No. of } \\
\text { pts. }\end{array}$ & $\begin{array}{c}\text { Intense } \\
\text { Pain }\end{array}$ & Percentage \\
\hline $\begin{array}{c}\text { Olivares-Tores et } \\
\text { al. }\end{array}$ & 52 & 3 & $5.8 \%$ \\
\hline Dey et al. & 38 & 3 & $7.9 \%$ \\
\hline Present study & 23 & 1 & $4.35 \%$ \\
\hline \multicolumn{2}{|r|}{ Table 7: Showing the incidence of intense } \\
pain during pleurodesis
\end{tabular}

In iodopovidone group more patients had severe grades of pain during pleurodesis, whereas in oxytetracycline group more number of patients had milder degree of pain during pleurodesis. This could probably mean that iodopovidone causes more pleural inflammation as compared to oxytetracycline.

Fever was another side effect recorded in pleurodesis. Incidence of fever after pleurodesis in previous studies varies from 10 to $59 \%$. In the present study, total incidence of fever was $32 \%$. In oxytetracycline group, it is $36 \%$ and iodopovidone group it is $27 \%$.

The incidence of fever in the present study is comparable to the incidence in other published studies. Incidence of fever in oxytetracycline group is $36 \%$ and in iodopovidone group it is $27 \%$. The incidence of fever as a side effect with both agents is comparable as difference is statistically insignificant ( $p$ $<0.03$ ).

\section{Hypotension}

In this study, 2 patients developed hypotension during procedure and both of them were in iodopovidone group. In various published studies transient hypotension has been reported after iodopovidone pleurodesis as shown in Table 8.

\begin{tabular}{|c|c|c|c|}
\hline Study & $\begin{array}{c}\text { No. of } \\
\text { pts. }\end{array}$ & Hypotension & Percentage \\
\hline $\begin{array}{c}\text { Olivares-Tores } \\
\text { et al. }\end{array}$ & 52 & 3 & $5.8 \%$ \\
\hline Dey et al. & 38 & 3 & $7.9 \%$ \\
\hline Present Study & 22 & 2 & $9.09 \%$ \\
\hline \multicolumn{3}{|c|}{ Table 8: Showing incidence of hypotension after } \\
iodopovidone pleurodesis \\
\hline
\end{tabular}

In both the above mentioned studies, hypotension was preceded by intense pleuritic chest pain. In the present study, patients who developed hypotension had severe degree of chest pain during introduction of sclerosing agent. There were no ECG changes during the hypotension, it was transient and blood pressure was restored to its pre-procedure value without any complications. These patients were neither hypertensives nor had history of any cardiac illness in the past. They did not require inotropic support; symptomatic treatment with intravenous fluids and leg elevation restored the blood pressure to normal level.

\section{Mortality}

Two patients expired within 30 days of the procedure, one in each group, but these deaths were unrelated to the procedure. One patient expired due to pulmonary embolism and the other had cerebrovascular accident.

\section{CONCLUSIONS}

Success rate of iodopovidone pleurodesis is superior to oxytetracycline pleurodesis ( $95 \%$ vs $81 \%$ ); however, it is statistically not significant. We would like to concede that a larger sample size would have made the results more statistically significant. It can be safely concluded that iodopovidone is as good as oxytetracycline for chemical pleurodesis. Iodopovidone is easily available even in remote areas and is cheaper as compared to oxytetracycline. Pleurodesis with iodopovidone can be performed under local anaesthesia with excellent tolerance.

\section{ACKNOWLEDGEMENT}

The authors would like to thank the Dean, Goa Medical College, Goa, for permitting us to conduct this study.

\section{BIBLIOGRAPHY}

1. Roberts ME, Neville E, Berrisford RG, et al. Management of malignant pleural effusion: BTS pleural disease guideline 2010. Thorax 2010;65 (Suppl 2):ii32-ii40.

2. Nahid P, Broaddus VC. Liquid and protein exchange. In: Light RW, Lee YC (Gary), Eds.: Textbook of Pleural Diseases. London: Arnold Publishers; 2003;33-44.

3. Noppen M. Normal volume and cellular contents of pleural fluid. Curr Opin Pulm Med 2001;7:180-182.

4. Haddad FJ, Younes RN, Gross JL, et al. Pleurodesis in patients with malignant pleural effusions: talc slurry or bleomycin? Results of a prospective randomized trial. World J Surg 2004;28:749-752.

5. Rubinson RM, Bolooki H. Intrapleural tetracycline for control of malignant pleural effusion: a preliminary report. South Med J 1972;65:847-849.

6. Robinson LA, Fleming WH, Galbraith TA. Intrapleural doxycycline control of malignant pleural effusions. Ann Thoracic Surg 1993;55:1115-1121.

7. Dollinger MR, Krakoff IH, Karnofsky DA. Quinacrine (Atabrine) in the treatment of neoplastic effusions. Ann Int Med 1967;66:249-257.

8. Paschoalini Mda S, Vargas FS, Marchi E, et al. Prospective randomized trial of silver nitrate vs talc slurry in pleurodesis for symptomatic malignant pleural effusions. Chest 2005 Aug;128(2):684-89.

9. Bilaceroglu S, Cagirici U, Perim K, et al. Corynebacterium parvum pleurodesis and survival is not significantly influenced by pleural $\mathrm{pH}$ and glucose level. Monaldi Arch Chest Dis 1998 Feb;53(1):14-22.

10. Walker-Renard PB, Vaughan LM, Sahn SA. Chemical pleurodesis for malignant pleural effusions. Ann Int Med 1994;120:56-64.

11. Sadikot RT, Greene T, Meadows K, et al. Recurrence of primary spontaneous pneumothorax. Thorax 1997;52:805-809.

12. Gobbel WG Jr, Rhea WG Jr, Nelson IA, et al. Spontaneous Pneumothorax. J Thorac Cardiovasc Surg 1963;46:331345.

13. Videm V, Pillgram-Larsen J, Ellingsen 0, et al. Spontaneous pneumothorax in chronic obstructive pulmonary disease: complications, treatment and recurrences. Eur J Respir Dis 1987;71:365-371.

14. Light RW, O'Hara VS, Moritz TE, et al. Intrapleural tetracycline for prevention of recurrent spontaneous pneumothorax. Results of a Department of Veterans Affairs Cooperative Study. JAMA 1990 Nov 7;264 (17): 2224-30.

15. Suarez PM, Gilart JL. Pleurodesis in the treatment of pneumothorax and pleural effusion. Monaldi Arch Chest Dis 2013 Jun;79(2):81-86. 
16. Alfageme I, Moreno L, Heutas C, et al. Spontaneous pneumothorax. Long term results with tetracycline pleurodesis. Chest 1994;106:347-350.

17. Sherman S, Grady KJ, Seidman JC. Clinical experience with tetracycline pleurodesis of malignant pleural effusions. South Med J 1987;80:716-719.

18. Walker-Renard PB, Vaughan LM, Sahn SA. Chemical pleurodesis for malignant pleural effusions. Ann Intern Med 1994;120:56-64.

19. Olivares-Torres CA, Laniado-Laborin R, Chavez-Garcia C, et al. Iodopovidone pleurodesis for recurrent pleural effusion. Chest 2002;122:581-583.
20. Dey A, Bhuniya S, Datta Chaudhuri A, et al. Iodopovidone pleurodesis: experience of a tertiary hospital in Kolkata. Singapore Med J 2010;51(2):163-165.

21. Morales-Gomez J, Tellez-Becerra JL, Martinez-Ormeno JE, et al. Pleurodesis with iodopovidone in malignant pleural effusions. Rev Inst Nal Enf Resp Mex 1993;6:7174.

22. Kelly-Garcia J, Roman-Berumen JF, Ibarra-Perez C. Iodopovidone and bleomycin pleurodesis for effusion due to malignant epithelial neoplasms. Arch Med Res 1997;28:583-585 